\title{
EFFECT OF THE INSECTICIDE ABAMECTIN ON THE METABOLIC ACTIVITY OF CHLORELLA VULGARIS BEYERINCK
}

\author{
Fathi A. A. and Al-Fredan M. A. \\ Biology Department, College of Science, King Faisal University, Al-Hassa, Saudi \\ Arabia
}

\begin{abstract}
This investigation studied the effects of Abamectin on the growth and some physiological activities of Chlorella vulgaris. The results showed that growth parameters decreased with increase in Abamectin concentrations. All the applied treatments of Abamectin strongly reduced the total sugars contents, total protein and total amino acids of Chlorella vulgaris. The drop was more prominent and highly significant at higher dose. The data also showed that Abamectin treatment suppressed the activity of acid phosphatase, alkaline phosphatase, GOT and GPT of Chlorella vulgaris.
\end{abstract}

\section{Introduction}

Today environmental problems are multiple and complex, especially those arising from the disposal of identification and the assessment of the toxicity of such substances like pesticides. Pesticides differ from most industrial organic chemicals in that they are brought into the environment with the explicit intention of exerting toxic effects on one or more target organisms. Unfortunately, their toxicity is usually not limited to the location where they are applied. They reach other locations and environmental compartments through various physical transport processes, adversely affecting organisms that happen to be present (Deneer, 2000; Jianyi et al., 2002; Kamel et al., 2007 ).

Algae composing the primary producer level are of initial importance in providing the energy that sustains invertebrates and fish in most aquatic ecosystems. The action of toxic substances on algae is therefore not only important for the organisms themselves, but also for other links in the food chain. Algal toxicity tests are increasingly being used in bioassay test batteries for environmental management of chemical discharges and it has been observed in several studies that for a large variety of chemical substances. Algal tests are relatively sensitive bioassay tools (Seguin et al., 2001; Ma and Liang, 2001; Ma et al., 2002; Mostafa and Helling, 2002; Friesen Pankratz et al., 2003; Fathi, 2003).

Recently, a number of acaricides were registered at the Ministry of Agriculture in Saudi Arabia to control the mite Oligonychus afrasiaticus, which 
infest dates and causes severe damage. Among these acaricides, abamectin, flufenoxuron and amitraz are widely applied on dates to control the mite infestation. Due to the large amount of dates consumed by Saudi residents (an average of 10 dates daily per person), the search for safe pesticides with negligible residual deposits has always been preferred (Kamel et al., 2007).

The avermectins are a family of macrocyclic lactones, produced by the soil organism Streptomyces avermitilis, which were discovered in the mid-1970's as a direct result of a screening effort for natural products with anthelmintic properties. Insecticide Abamectin belongs to the family avermectins. It contains at least $80 \%$ avermectin B1a and not more than $20 \%$ avermectin B1b. Abamectin acts by stimulating the release of $\mathrm{c}$-aminobutyric acid thus causing paralysis (Turner and Shaeffer, 1989). It is used to control motile stages of mites and some other insects on fruits and vegetables and has limited plant systemic activity. Abamectin is highly unstable to light and has been shown to photodegrade rapidly on plant and soil surfaces and in water following agricultural applications. Abamectin was also found to be degraded readily by soil microorganisms (Lasota and Dybas, 1990).

Abamectin, widely used as a veterinary anthelmintic, medicine against a variety of animal parasites and insects, can runoff from the sites of application and becomes an aquatic pollutant (Tatjana and Nevenka, 2006). The aim of this study was to identify the toxicity of abamectin on the growth and some physiological activities of the green alga Chlorella vulgaris.

\section{Material and methods}

\section{Organism and culture condition}

Chlorella vulgaris Beyerinck was isolated from Al-Asfar Lake, Al-Hassa, Saudi Arabia. Isolation and purification was made by dilution and plating technique. The alga was grown in $250-\mathrm{mL}$ flasks containing $100 \mathrm{~mL}$ Kuhl's medium (1962), and incubated in an illuminated incubator (Precision, USA) at $22^{\circ} \mathrm{C}$, and irradiance at $150 \mu \mathrm{mol} \mathrm{m} \mathrm{m}^{-2}$, provided by cool white fluorescent lamps set on 14:10 h photoperiod. All cultures were shaken twice daily to prevent cells from clumping. Sterile technique was used at all times.

\section{Treatments}

Abamectin (1.8\% EC) Arab Industrial Company, Dammam, Saudi Arabia was used in this study. The main structural characteristics and structural formula of Abamectin were presented in (Table 1 and Figure 1). A standard stock solution of Abamectin was prepared by dissolving Abamectin in acetone. Appropriate volumes of the standard stock solution were added to culture flasks $(250-\mathrm{mL})$. Medium was then added and flasks were left for one hour to obtain aqueous solutions of $0,0.1,0.2,0.4,0.6,0.8$, and $1.0 \mathrm{mM}$. Preliminary experiments were carried out to determine the suitable range of pesticide concentrations. All cultures (three per treatment) received identical inocula and were incubated under 
the prescribed growth conditions. At the end of the incubation period the cultures were harvested and washed several times by distilled water to measure the various parameters. The calculated values are the mean of triplicates and the standard deviation was less than $50 \%$ of these mean values.

Table (1): The main structural characteristics of abamectin.

\begin{tabular}{|l|l|}
\hline Common name & $\begin{array}{l}\text { abamectin (BSI, draft E-ISO, ANSI); abamectine } \\
((f) \text { draft F-ISO }\end{array}$ \\
\hline Chemical Name & avermectin B1 \\
\hline Appearance & $\begin{array}{l}\text { Abamectin is a colorless to yellowish crystalline } \\
\text { powder }\end{array}$ \\
\hline Molecular Weight & 873.11 \\
\hline Water Solubility & Insoluble \\
\hline Solubility in Other Solvents & $\begin{array}{l}\text { v.s. in acetone, methanol, toluene, chloroform, } \\
\text { and ethanol. }\end{array}$ \\
\hline Melting Point & $150-155^{\circ} \mathrm{C}$ \\
\hline Vapor Pressure & Negligible \\
\hline Composition & $\begin{array}{l}\text { A mixture containing }{ }^{3} 80 \% \text { avermectin } \mathrm{B}_{1 \mathrm{a}} \text { (i) and } \\
£ 20 \% \text { avermectin } \mathrm{B}_{1 \mathrm{~b}} \text { (ii). }\end{array}$ \\
\hline Chemical Class & Insecticide/miticide \\
\hline Acute toxicity & $\begin{array}{l}\text { Abamectin is highly toxic to insects and may be } \\
\text { highly toxic to mammals as well }\end{array}$ \\
\hline Effects on birds & Abamectin is practically nontoxic to birds \\
\hline Effects on aquatic organisms & $\begin{array}{l}\text { Abamectin is highly toxic to fish and extremely } \\
\text { toxic to aquatic invertebrates }\end{array}$ \\
\hline
\end{tabular}

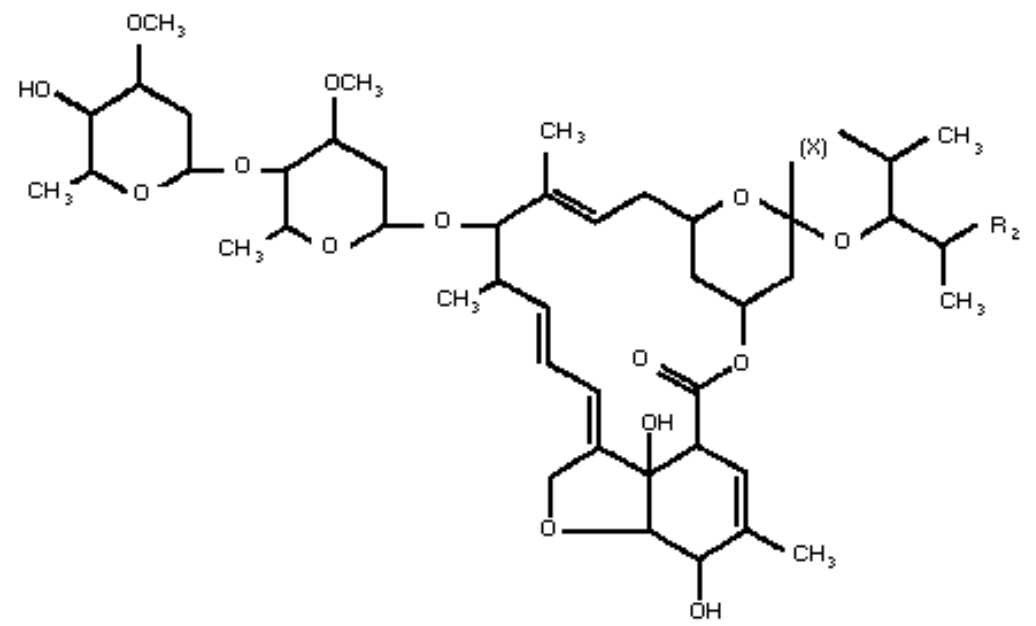

Figure (1): Structural formula of Abamectin 


\section{Growth}

Growth was measured in terms of cell number using a Haematocytometer, which was used for calculation of growth rate (Nichols 1973). Chlorophyll a was estimated according to Metzner et al. (1965).

\section{Photosynthetic oxygen evolution}

Photosynthetic oxygen evolution was measured at $27{ }^{\circ} \mathrm{C}$ by bubble counting method Using Cobra3-Basic-Unit (Phywe, GmbH and Co. KG). Prior to the experiment the algae were resuspended in the free incubation L Kuhl's medium and the oxygen bubble counting was measured after the addition of Abamectin concentrations.

\section{Biochemical analysis}

The anthrone method (Roe, 1955) was applied for total carbohydrate estimation using fresh material and glucose as a standard. Total amino acid content was determined according to Moore and Stein (1948). Total protein was measured according to Lowry et al. (1951).

\section{Algal extraction for enzyme assay}

Fresh algal samples were instantly ground immediately after the experimental period with a known volume of distilled water and little of pure acid washed sand. Samples were then centrifuge at 10,000rpm for 15 minutes, made up to a known volume and frozen. The methods of Bergmeyer (1974) were adopted for the estimation of both glutamic oxaloacetic transaminase (GOT) and glutamic pyruvate transaminase (GPT). Both acid and alkaline phosphatases were estimated in the same extract by estimating the liberated phosphorous colorimetrically at $700 \mathrm{~nm}$ by the sulphite metol method (Burton and Riley, 1954).

\section{Statistics}

Results were tested by one-way analysis of variance (ANOVA). ANOVA effects and treatments differences were considered significant when $\mathrm{P}<0.05$.

\section{Results and Discussion}

Pesticides play an important role in agricultural practices. Increase in the use of pesticides has elicited extensive research into pesticide effects on nontarget organisms such as algae. Therefore, their potential effects on the aquatic primary producers are particularly important, and have to be studied in ecotoxicological experiments (Berard, 1996; Ma and Chen, 2005).

Results illustrated in Figure (2) clearly revealed that the growth rate $(\mu)$ of Chlorella vulgaris irrespective of some minor fluctuations, decreased with increased Abamectin concentrations in the culture medium; the drop was more prominent and highly significant at the higher than lower doses. A similar inhibitory effect on cell number by different pesticides were reported, with 
Chlamydomonas (Cain and Cain, 1984); Scenedesmus obliqnus and Chlorella pyrenoidosa (Ma et al., 2002); Chlorella kesslerei and Anabaena inaequalis (Mostafa and Helling, 2002); Scenedesmus bijuga (Fathi, 2003); Tolypothrix scytonemoides (Rajendran et al., 2007). Figure (2) further shows that the Chl.a content of Chlorella vulgaris decreased continuously with increasing Abamectin concentration. This reduction was significant at the highest concentration (1.0 $\mathrm{mM})$. These findings are in agreement with several previously published data (Hammouda, 1994; Seguin et al., 2001; Mostafa and Helling, 2002; Fathi, 2003; Rajendran et al., 2007). Reduction of chlorophyll and phycobiliprotein contents in cyanobacteria by insecticide treatment has been reported earlier (Marco and Orus, 1993). Growth and photosynthetic pigments, i.e., chlorophyll- $a$, carotenoids and phycocyanin were adversely affected by pesticides treatment and the inhibition was found to be dose dependent (Prasad, et al., 2005; Rajendran et al., 2007).

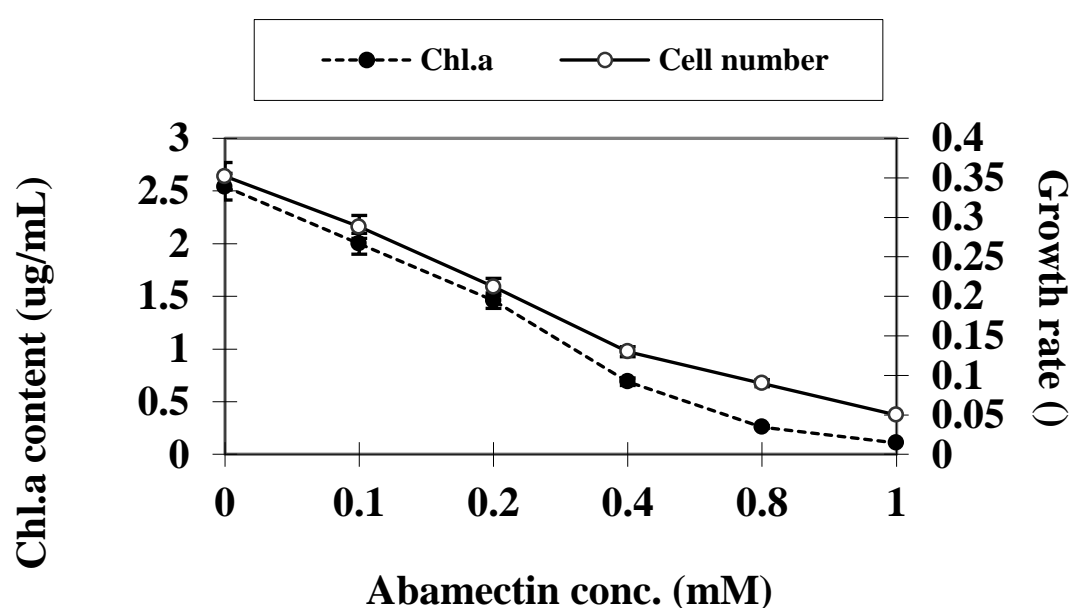

Figure (2): Effect of Abamectin on Chlorophyll $a$ and Growth rate $(\mu)$ of Chlorella vulgaris Beyerinck at various concentration after 7 days growth period. Vertical bars indicate $S E, n=3$.

The interference of Abamectin with growth and Chl. $a$ was further clarified by testing the effect of the insecticide on photosynthetic oxygen evolution, which indicate a remarkable reduction in the value by increasing the concentration of the insecticide (Fig. 3). The highest inhibitory effect of Abamectin on photosynthetic oxygen evolution (about 95\% inhibition) was detected at the concentration of $1.00 \mathrm{mM}$. Pesticide induced reduction in photosynthetic oxygen evolution might be due to inhibition of PS II activity as a result of damage to the thylakoid lamellar membrane or by disruption of water 
splitting machinery of the photosynthetic apparatus (Singh and. Tiwari, 1988). Marco et al. (1990) reported that the photosynthetic activity in Anabaena PCC 7119 was unaffected by trichlorfon treatment, however a slight effect in Gloeocapsa sp. was detected after $24 \mathrm{~h}$ of exposure.

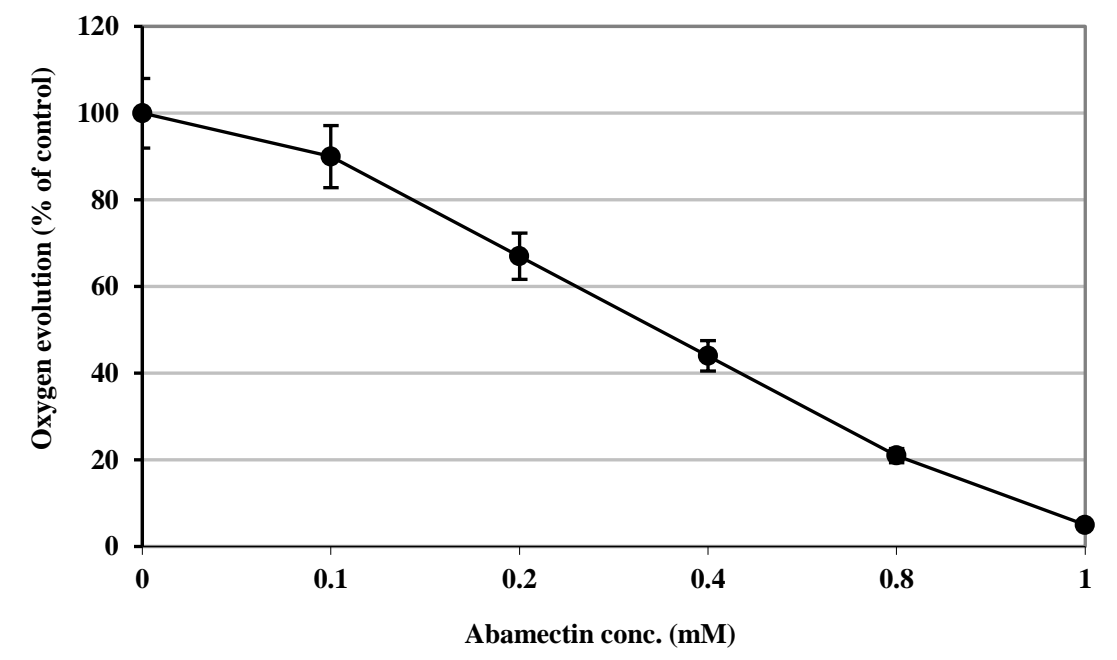

Figure (3): Effect of different concentrations of Abamectin on photosynthetic oxygen evolution of Chlorella vulgaris Beyerinck. Vertical bars indicate SE, $n=3$

Data presented in Table (2) show that the total sugars contents of Chlorella vulgaris increased following treatment with the lower concentrations of Abamectin. However the amounts of these fractions appeared to be significantly decreased at the highest concentration of the tested insecticide. The inhibitory effect of relatively high concentrations of Abamectin on total sugars production in the present study might be due to retardation in the rate of $\mathrm{CO}_{2}$ photoassimilation (Mansour et al., 1993). Similarly, Mansour et al. (1993) reported that relatively high concentration $(3.5 \mathrm{ppm})$ of butachlor significantly decreased the levels of carbohydrate fraction of Nostoc kihlmani. However, Eladel et al. (1999) showed that no consistent dose-dependent of thiobencarb changes occurred in total carbohydrate of Protosiphon botryoides.

Results in Table (2) showed that applying Abamectin to Chlorella suppressed the total protein content in comparison to control values. This effect is more pronounced at the higher doses. Eladel et al. (1999) reported that at 3 $\mathrm{mgL}^{-1}$ of thiobencarb, the protein content of Protosiphon botryoides decreased. Although the modes (s) of action of pesticides are not well understood, they seem to inhibit fatty acids and protein synthesis (Tomlin, 1994; Eladel et al., 
1999), or due to the denaturation of proteins induced by them (Bueno et al., 2004, Rajendran et al., 2007).

Table (2): Effect of Abamectin on some physiological characteristics of Chlorella vulgaris Beyerinck at various concentrations after $\mathbf{7}$ days growth period. Results of one-way ANOVA comparison of treatments to controls indicate $* \mathbf{P}<0.05 ; * * \mathbf{P}<$ $0.01 ; * * * \mathrm{P}<0.001$.

\begin{tabular}{|c|c|c|c|}
\hline $\begin{array}{c}\text { Conc. } \\
(\mathbf{m M})\end{array}$ & $\begin{array}{c}\text { Total protein } \\
{[\% \text { dry. mass] }}\end{array}$ & $\begin{array}{c}\text { Total sugars } \\
{[\% \text { dry. mass }]}\end{array}$ & $\begin{array}{c}\text { Total amino acids } \\
{[\% \text { dry. mass] }}\end{array}$ \\
\hline 0.0 & $37.61 \pm 0.10$ & $72.22 \pm 0.30$ & $28.26 \pm 0.15$ \\
\hline 0.1 & $33.52 \pm 0.15$ & $44.32 \pm 0.25$ & $26.54 \pm 0.10$ \\
\hline 0.2 & $28.65 \pm 0.10$ & $36.62 \pm 0.10$ & $18.00 \pm 0.00$ \\
\hline 0.4 & $20.44 \pm 0.20$ & $30.33 * \pm 0.20$ & $24.44 \pm 0.00$ \\
\hline 0.8 & $12.81 * * \pm 0.11$ & $20.62 * * * \pm 0.20$ & $16.21 * * \pm 0.00$ \\
\hline 1.0 & $12.00 * * \pm 0.10$ & $18.64 * * \pm 0.20$ & $7.66 * * \pm 0.00$ \\
\hline $\begin{array}{c}\text { One-Way } \\
\text { ANOVA }\end{array}$ & $* * *$ & $* *$ & $* *$ \\
\hline
\end{tabular}

All the values are mean of three replicates $[n=3] \pm S E$

The results show successive increase in total amino acids content as Abamectin concentration increased between 0.1 and $0.4 \mathrm{mM}$, and the maximum value appeared at $0.2 \mathrm{mM}$ (Table 2). Concentrations higher than $0.4 \mathrm{mM}$ of Abamectin were inhibitory. Higher concentrations of pesticides were inhibitory to total amino acids of Nostoc muscorum. In addition, the amino acids produced in algal cells differed quantitatively and qualitatively according to the type of alga and conditions of cultivation (El-Ayouty and Ezzat, 1991; Fathi, 2003). Soliman et al. (1994) reported that the synthesis of some major amino acids depends on the provision of carbon skeleton from TCA cycle, which can be indirectly affected by the herbicide.

Data presented in Figure (4) show that Abamectin treatment suppressed the activity of acid and alkaline phosphatase of Chlorella vulgaris. Moreover, the highest doses of Abamectin were more suppressive to the activity of both enzymes. Regarding too GOT and GPT enzymes, the lower doses of Abamectin $(0.1$ and $0.2 \mathrm{mM})$ decreased the activity of these enzymes. Above $0.8 \mathrm{mM}$ of Abamectin the enzyme activity was significantly inhibited (Fig. 5). Mansour et al., (1993) reported that GOT and GPT activities of some Cyanophyta were markedly enhanced by different concentrations of butachlor, oxadiazon or thiobencarb. Soliman et al. (1994) revealed that malate dehydrogenase of Nostoc kihlmani and Anabaena oscillarioides increased significantly in response to treatment with low and moderate doses of pesticides, while inhibited with higher doses. Similarly, glutamine synthetase activity was suppressed by Propanil in $N$. muscorum (Singh and Tiwari, 1988; Rajendran et al., 2007). 


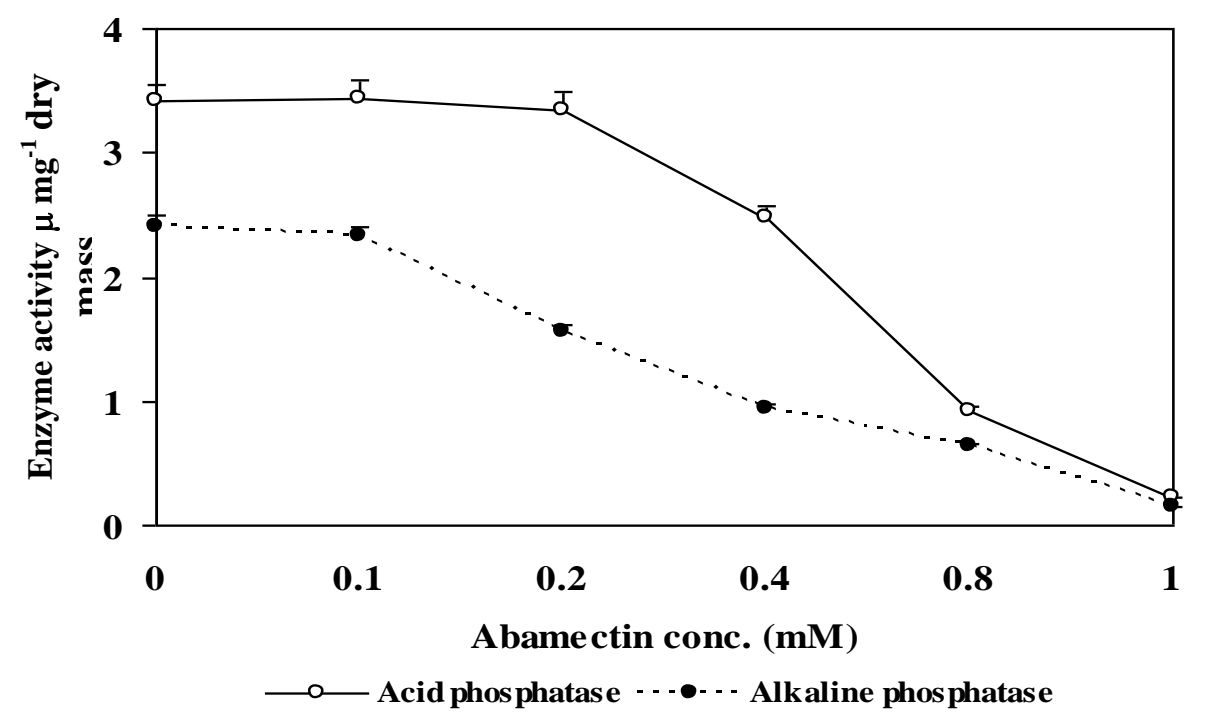

Figure (4): Effect of different concentrations of Abamectin on acid and alkaline phosphatase activity in Chlorella vulgaris Beyerinck at various concentrations after 7 days growth period. Vertical bars indicate $\mathrm{SE}, \mathrm{n}=3$

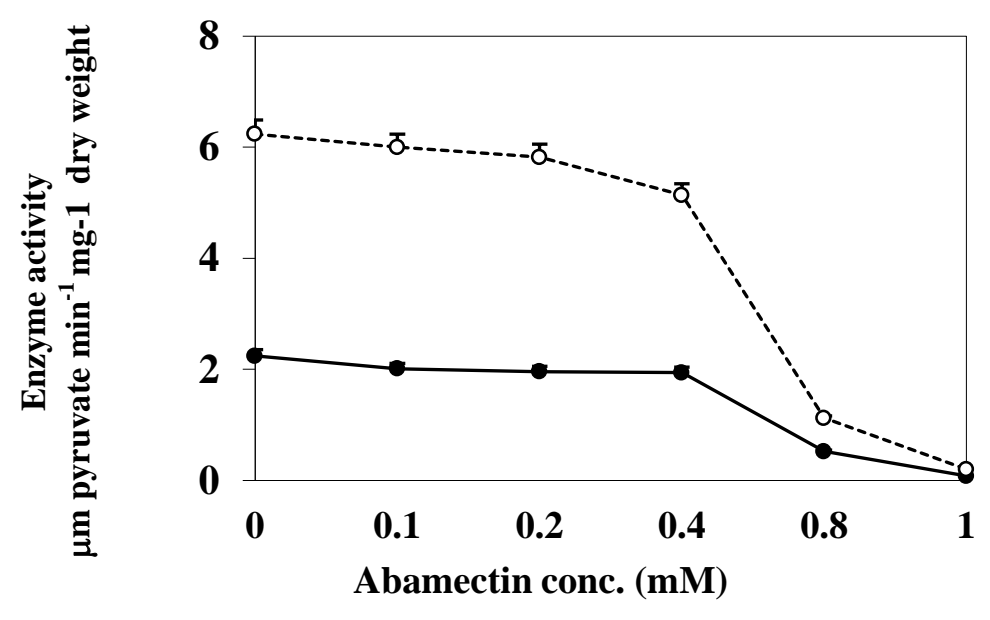

\footnotetext{
$\longrightarrow$-GOT

---o--- GPT

Figure (5): Effect of different concentrations of Abamectin on GOT and GPT activity in Chlorella vulgaris Beyerinck at various concentrations after 7 days growth period. Vertical bars indicate $\mathrm{SE}, \mathrm{n}=3$ 
On the other hand, glutamine synthetase activity was enhanced in $N$. calcicola in the presence of Bavistin, Phosphomidon, and Rogar (Anand and Subramanian, 1997).

\section{Acknowledgement}

In memory of Prof. Dr. Imam Kobbia, We thank the Deanship of Scientific Research, King Faisal University for financial support (Grant No.7113).

\section{References}

Anand, N. and Subramanian, D. (1997). Effect of certain pesticides on the physiology of Nostoc calcicola. Phykos, 36:15-20.

Berard, A. (1996). Effect of organic four solvents on natural phytoplankton assemblages: consequences for ecotoxicological experiments on pesticides. Bulletin of Environmental Contamination and Toxicology, 57: 183-190.

Bergmeyer, H.U. (1974). Methods of Enzymatic Analysis. Vol.2. Academic Press.

Bueno, M.; Fillat, M. F.; Strasser, R. J.; Maldonado-Rodriguez, R.; Marina, N.; Sminek, H.; Gomez-Moreno, C. and Barja, F. (2004): Effects of lindane on the photosynthetic apparatus of the cyanobacterium Anabaena: Xuorescence induction studies and immunolocalization of ferredoxinNADP+ reductase. Environ. Sci. Pollut. Res. Int., 11: 98-106.

Burton, J.O. and Riley, J. P. (1954). In " Modern Methods of plant Analysis" by Paech, K. and Tracey. M.V., 2, 370- Springer Verlag. Berlin.

Cain, J. R. and Cain, R. K. (1984). Effects of five insecticides on the zygospores germination and growth of the green alga Chlamydomonas moewusii. Bulletin of Environmental Contamination and Toxicology, 33:571-574.

Deneer, J. W. (2000). Toxicity of mixtures of pesticides in aquatic systems. Pestic. Manag. Sci., 56: 516-520.

Eladel, H. H.; William, J. H. and Kobbia, I. A. (1999). Effect of thiobencarb on growth and photosynthesis of the soil alga Protosiphon botryoides (Chlorophyta). J. Appl. Phycol., 10:547-554.

El-Ayouty, Y. M. and Ezzat, S. M. (1991). Effect of the herbicide prometryn on the metabolic activity of the Cyanobacterium Nostoc musocorum. Egypt. J. Microbiol., 26(2): 195-208.

Fathi, A. A. (2003). Some metabolic activities in the green alga Scenedesmus bijuga as affected by the insecticide Trichlorfon. Protistology, 3(2):80-86.

Friesen Pankratz, B.; Doebel, C.; Farenhorst, A. and Goldsborough, L. G. (2003). Interactions between algae (Selenastrum capricornutum) and pesticides: implications for managing constructed wetlands for pesticides removal. J. Environ. Sci. Health B., 38:147-155.

Hammouda, H. E. (1994). Inhibition of ammonium and nitrate uptake by Trichlorfon in Gloeocapsa sp. Mans. Sci. Bull. (B. Biology), 21(1):87-80. 
Jianyi, M.; Rongquan, Z.; Xu, L. and Shufeng, W. (2002). Differential Sensitivity of Two Green Algae, Scenedesmus obliqnus and Chlorella pyrenoidosa, to12 Pesticides. Ecotoxicology and Environmental Safety, 52: 57-61.

Kamel, A. A.; Al-Dosary, S.; Ibrahim, S. and Asif A. M. A. (2007). Degradation of the acaricides abamectin, flufenoxuron and amitraz on Saudi Arabian dates. Food Chemistry, 10:1590-1593.

Kuhl, A. (1962). Zur physiologie der Speicherung Kondensierter anorganischer Phosphate in Chlorella. Vorlrag Bot. Hrsg. Deut. Botan. Ges. (N.C.), 1:157-166.

Lasota, J. A. and Dybas, R. A. (1990). Abamectin as a pesticide for agricultural use. Acta Leiden., 59(1-2):217-225.

Lowry, O. H.; Rosenbroug, N. J.; Farr, A. F. and Randall, R. J. (1951). Protein measurement with the Folin phenol reagent. J. Biol. Chem., 193:265-275.

Ma, J. and Chen, J. (2005). How to accurately assay the algal toxicity of pesticides with low water solubility. Environmental Pollution, 136:267273.

Ma, J. and Liang, W. (2001). Acute toxicity of 12 herbicides to the green algae Chlorella pyrenoidosa and Scenedesmus obliqnus. Bull. Environ. Contam. Toxicol., 67(3): 347-351.

Ma, J.; Zheng, R.; Xu, L. and Wang, S. (2002). Differential sensitivity of two green algae, Scenedesmus obliqnus and Chlorella pyrenoidosa, to 12 pesticides. Ecotoxicology and Environmental Safety, 52:57-61.

Mansour, F.A.; Soliman, A. I.; Shaaban-Dessouki, S. A. and Hussein, M. H. (1993). Physiological effects of rice filed pesticides: Butachlor, Oxadiazon and Thiobencarb, on Nostoc kihlmani and Anabaena oscillarioides. IChanges in carbohydrates content, PMASE and GOT activities. Mans. Sci. Bull. (B. Biology), 20(2): 35-50.

Marco, E.; Martinez, F. and Orus, M. I. (1990). Physiological alterations induced by the organophosphorus insecticide trichlorfon in Anabaena PCC 7119 grown with nitrates. Environmental and Experimental Botany, 30:117-126.

Marco, E.; Orus, M. I. (1993). Trichlorfon-induced inhibition of nitrate and ammonium uptake in cyanobacteria. J. Exp. Bot., 44:501-508.

Metzner, H.; Rau, H.and Senger, H. (1965). Untersuchungen zur synchronisierbar karkeit einzellner- Pigment. Mangel Mutanten von Chlorella. Plant, 65:186-194.

Moore, S. and Stein, W. (1948). Photometric ninhydrine method for use in the chromatography of amino acids. J. Biol. Chem., 17: 367-388. 
Mostafa, F. I. and Helling, C. S. (2002). Impact of four pesticides on the growth and metabolic activities of two photosynthetic algae. J. Environ. Sci. Health. 37: 417-444.

Nichol's, H. W. (1973). Growth media fresh water. In stein, J.R. (Ed) handbook of physiological methods culture method, and growth measurements. Cambridge University press, Cambridge, UK.7-24.

Prasad, S. M.; Kumar, D. and Zeeshan, M. (2005). Growth, photosynthesis, active oxygen species and antioxidants responses of paddy Weld cyanobacterium Plectonema boryanum to endosulfan stress. J. Gen. Appl. Microbiol., 51:115-124.

Rajendran, U. M.; Elango, K. and Anand, N. (2007). Effects of a fungicide, an insecticide, and a biopesticide on Tolypothrix scytonemoides. Pesticide Biochemistry and Physiology, 87:164-171.

Roe, J. H. (1955). The determination of sugar in blood and spinal fluid with anthrone reagent. J. Biol. Chem., 212: 335-343.

Seguin, F.; Leboulanger, C.; Druart, J. C. and Berard, A. (2001). Effects of Atrazine and Nicosulfuron on Phytoplankton in systems of increasing complexity. Arch. Environ. Contam. Toxicol., 40:198-208.

Singh, L. J. and Tiwari, D. N. (1988). Effect of selected rice Weld herbicides on photosynthesis, respiration and nitrogen assimilating enzyme systems of paddy soil diazotrophic cyanobacteria. Pestic. Biochem. Physiol., 31:120128.

Soliman, A. I.; Shaaban-Dessouki, S. A.; Mansour, F. A. and Hussein, M. H. (1994). Physiological effects of rice filed herbicides: Butachlor, Oxadiazon and Thiobencarb, on Nostoc kihlmani and Anabaena oscillarioides. IIIComparative Effect on photosynthesis, respiration and net production rates. Mans. Sci. Bull. (B. Biology), 21(1): 55-71.

Tatjana, T. and Nevenka, K. (2006). Abamectin in the aquatic environment. Ecotoxicology, 15:495-502.

Tomlin, C. (1994). The Pesticide Manual, Incorporating the Agrochemical Handbook. (tenth Ed) The British Crop Protection Council and The Royal Society of Chemistry.

Turner, M. J. and Shaeffer, J. M. (1989): Biochemistry. In W. C. Campbell (Ed.), Ivermectin and abamectin (pp. 73-88). New York, NY: Springer. 


\title{
تأثير المبيد الحشري اباميكتين على النشاط الايضي لطحلب الكلوريلا فولجارس
}

\author{
عادل أحمد فتحي ومحمد عبد الوهاب الفريدان \\ قسم الأحياء - كلية العلوم - جامعة الملك فيصل \\ المعلكة العربية السعودية
}

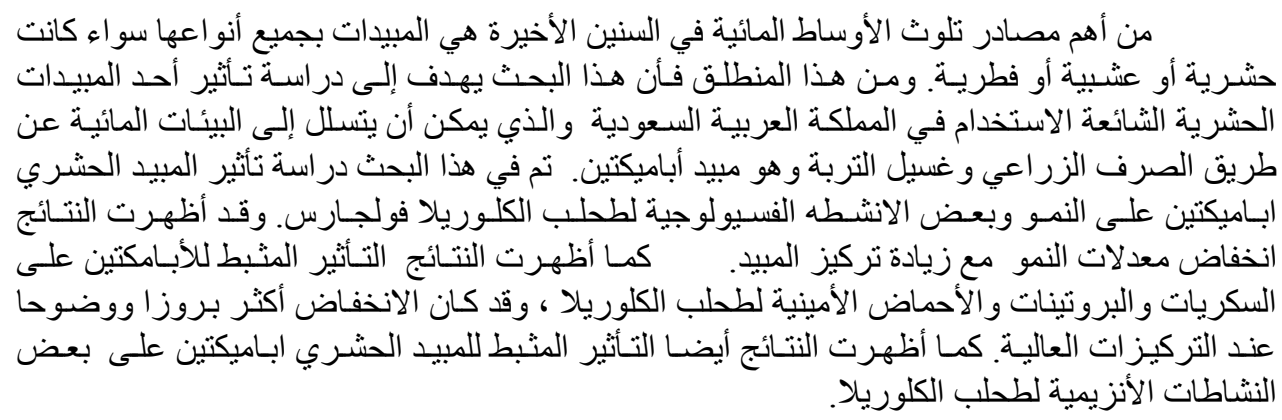

